\title{
RESTORATIVE JUSTICE, EUTHANASIA, AND ASSISTED SUICIDE: A NeW Arena for Restorative Justice AND A NeW PATH FOR END OF LIFE LAW AND POLICY IN CANADA
}

\author{
JENNIFER J. LLEWELLYN* AND JOCELYN DOWNIE**
}

This article examines the current Canadian legal approach to euthanasia and assisted suicide, highlights some of the problems with it, and offers a novel alternative to the current traditionally criminalized prohibitive regime. The authors first describe a restorative justice approach and explain the differences between such an approach and the traditional approach currently in use. They then explain how a restorative justice approach could be implemented in the arena of assisted death, acknowledging the potential challenges in implementation. The authors conclude that taking a restorative justice approach to euthanasia and assisted suicide could enable movement in the seemingly intractable public policy debates about these issues, lead to more effective and compassionate responses to cases of euthanasia and assisted suicide, and prompt policy and practice reform that enables society to better care for individuals at the end of life.
Cet article examine l'approche juridique canadienne actuelle à l'égard de l'euthanasie et du suicide assisté, en souligne certains problèmes et propose une alternative unique au régime traditionnel prohibitif et criminalisé qui existe aujourd'hui. Les auteurs commencent par décrire une approche de justice réparatrice et expliquent les différences entre cette approche et l'approche traditionnelle qui est actuellement en vigueur. Ils expliquent ensuite de quelle manière une approche réparatrice pourrait être mise en place dans le domaine de la mort assistée, tout en étant tenant compte de problèmes éventuels de mise en ouvre. Les auteurs concluent que l'approche réparatrice à l'égard de l'euthanasie et du suicide assisté pourrait donner un certain jeu dans le débat public à ce sujet, débat qui semble insoluble en apparence, et pourrait mener à des réactions plus efficaces et plus compatissantes aux cas d'euthanasie et de suicide assisté et amorcer une réforme politique et pratique permettant à la société de prendre mieux soins aux personnes en fin de vie.

\section{TABLE OF ConTENTs}

I. INTRODUCTION $\ldots \ldots \ldots \ldots \ldots \ldots \ldots \ldots \ldots \ldots \ldots \ldots \ldots \ldots \ldots$

II. THE CURRENT APPROACH TO EUTHANASIA

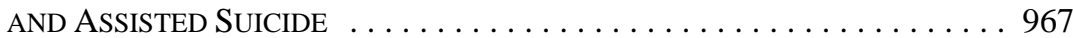

III. What Kind of Justice IS Restorative Justice? . . . . . . . . . . 971

IV. The DifFerence that Restorative Justice Might Make . . . . . . . . 972

A. A BRoAdER Understanding OF HARM . . . . . . . . . . . . . . . 972

B. ENHANCED ACCOUNTABILITY AND RESPONSIBILITY . . . . . . . . 973

C. A Proactive and Preventative Focus . . . . . . . . . . . . . 976

D. A MORE INCLUSIVE, PARTICIPATORY,

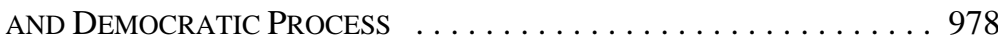

Director, Nova Scotia Restorative Justice Community University Research Alliance (NSRJ-CURA); Associate Professor, Schulich School of Law, Dalhousie University. She has written and published extensively on the theory and practice of restorative justice domestically and in transitional contexts. She has worked with the South African Truth and Reconciliation Commission, advised the Assembly of First Nations during the settlement process related to Indian residential schools abuse, and served as a senior consultant for the United Nations Development Program in the drafting and development of a National Restorative Justice policy for Jamaica.

Canada Research Chair in Health and Policy; Professor, Schulich School of Law and Faculty of Medicine, Dalhousie University. She is an elected fellow of the Canadian Academy of Health Sciences as well as the Royal Society of Canada. She has been engaged in research and advocacy around end of life law and policy for many years. Her book, Dying Justice: A Case for Decriminalizing Euthanasia \& Assisted Suicide in Canada (Toronto: University of Toronto Press, 2004), was awarded the Abbyann D. Lynch Medal in Bioethics by the Royal Society of Canada. 


\section{BuILDING A RESTORATIVE RESPONSE TO \\ EUTHANASIA AND ASSISTED SUICIDE $\ldots \ldots \ldots \ldots$. . . . . . . . . . . . . 980}

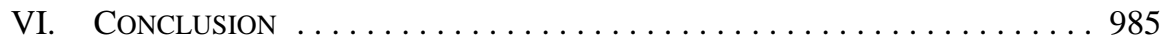

\section{INTRODUCTION}

Passions run high whenever the issue of society's response to euthanasia and assisted suicide is raised. Dialogue turns into debate and conversation turns into conflict. At fairly regular intervals, public discourse flares as a controversial case hits the media or politicians attempt to confront the public policy challenges that the issue creates. The names of Sue Rodriguez and Robert Latimer are familiar to most Canadians as, under the glare of the media spotlight, their cases worked their way up through the court system until each reached the Supreme Court of Canada. ${ }^{1}$ When a Special Committee of the Senate of Canada released a report on assisted death in Canada ${ }^{2}$ and when Irwin Cotler (then Minister of Justice) subsequently raised the possibility of initiating a public consideration of the issue, sparks flew. ${ }^{3}$ When the Quebec National Assembly actually engaged in a public consultation, ${ }^{4}$ the issue heated up again. And yet, despite these periodic flares, little if any progress has been made in resolving the deep controversy over the appropriate public policy stance with respect to euthanasia and assisted suicide in Canada. The issue is raised and people quickly take up their entrenched positions and rehearse long held arguments for or against the decriminalization of euthanasia and assisted suicide. A strong majority of Canadians have for decades supported decriminalization. ${ }^{5}$ Yet for decades federal politicians (the only ones with jurisdiction to proactively change the Criminal $\operatorname{Code}^{6}$ ), presumably fearing single issue right-to-life voters, have steered well clear of the issue. The question then arises - are we doomed to repeat the cycle of the issue being brought forward, an acrimonious debate ensuing, and ultimately no progress being made? Or is there another possible path?

In this article, we suggest that restorative justice might provide a new direction and a new way to resolve some of the myriad problems associated with the current approach taken to euthanasia and assisted suicide in Canada. To that end, we first describe the way euthanasia and assisted suicide are currently handled by the legal system in Canada. We then describe restorative justice and highlight some of the differences, both in substance and process,

Rodriguez v. British Columbia (A.G.), [1993] 3 S.C.R. 519; R. v. Latimer, 2001 SCC 1, [2001] 1 S.C.R. 3 [Latimer].

2 The Special Senate Committee on Euthanasia and Assisted Suicide, Of Life and Death - Final Report (Ottawa: Special Committee on Euthanasia and Assisted Suicide, 1995), online: Senate of Canada $<$ http://www.parl.gc.ca/common/Committee_SenRep.asp?Language=E\&Parl=35\&Ses=l\&comm_id=6>. Janice Tibbetts, "Cotler envisions law legalizing assisted suicide" National Post (3 November 2005) A5. Quebec National Assembly, "Select Committee on Dying with Dignity," online: Quebec National Assembly < http://www.assnat.qc.ca/en/travaux-parlementaires/commissions/csmd-39-1/index.html> . Ipsos News Center, News Release, “Canadians’ Views on Euthanasia” (6 November 1997), online: Ipsos News Center <http://www.ipsos-na.com/news/pressrelease.cfm?id=878>: "[W]hether a person who is terminally ill and wants to die before enduring the full course of the disease, should have the right to take their own life"; Canadian Press/Leger Marketing, How Canadians Perceive Euthanasia: Executive Report (Montreal: Leger Marketing, 2001) at 5, online: Leger Marketing <http://www.leger marketing.com/documents/SPCLM/010702ENG.pdf >: "In your personal opinion, should someone who has helped to die a member of his close family suffering from an incurable illness causing extreme pain be prosecuted?”; Ipsos News Center, News Release, “As Dr. Kevorkian Released, Just One Quarter (25\%) Believe Doctor-Assisted Suicide Should Be Illegal” (10 June 2007), online: Ipsos News Center $<$ http://www.ipsos-na.com/news/pressrelease.cfm?id=3526>; "Most Quebecers back legal euthanasia: poll” CBC News (22 November 2010), online: CBC News <http://www.cbc.ca/canada/montreal/story/ 2010/11/22/quebec-euthanasia-poll.html>. 
between the traditional approach currently in use and the proposed restorative approach. We follow this with an explanation of how a restorative justice approach could actually be implemented, while flagging important challenges in doing so. In the end, we conclude that taking a restorative justice approach to euthanasia and assisted suicide in Canada could enable movement in the seemingly intractable debate, and the adoption of a more effective and compassionate response to extraordinarily difficult situations.

\section{THE CURRENT ApProACH to EUTHANASIA AND ASSISTED SUICIDE}

At present, euthanasia and assisted suicide are clearly prohibited under the Criminal Code. ${ }^{7}$ Euthanasia is murder, and a conviction for murder carries a mandatory minimum life sentence with no possibility of parole for ten (for second degree murder) or 25 years (for first degree murder). ${ }^{8}$ Motive is irrelevant to the assessment of guilt, and consent to the act is no defence. ${ }^{9}$ While suicide itself is not a crime, counselling, aiding, and abetting someone else to commit suicide is, and a conviction for this crime can bring a sentence of up to 14 years in jail. ${ }^{10}$ Again, as with euthanasia, motive is irrelevant and consent is no defence.

Under the current approach to euthanasia and assisted suicide, the focus is on the individual who committed the act and they are "a suspect" before charges are laid, "the accused" once charged, and "an offender" or "criminal” once convicted. The person who died is considered a "victim." A victim, according to the Criminal Code, is "a person to whom harm was done or who suffered physical or emotional loss as a result of the commission of the offence." ${ }^{11}$ In the investigation, charging, and trial stages of the process, there is no scope for considering the wishes of the individual who died or the circumstances in which the request for euthanasia or assistance with suicide were made. Was the deceased imminently dying in intractable pain? Was the deceased a ten-year-old or a 50-year-old? Was the accused motivated by compassion or malice? Had society provided ready access to quality palliative care and home care support services, or was the deceased living in a rural community with no respite care and no health care providers for hundreds of miles? In the sentencing stage, the impact upon the deceased and those surrounding them (for example, their family) can be considered. For assisted suicide this can have profound implications as there is no mandatory minimum sentence. However, for euthanasia it can only affect the length of time to be served before the possibility of parole above the mandatory minima. A consideration of the impact on others is very limited and certainly does not extend beyond those close to the "victim.” Thus, the current approach polarizes the parties (the person who died and the accused) and limits the range of those included in the process (directly, the state and the accused; indirectly, the deceased; and even more indirectly those close to the deceased). ${ }^{12}$ It takes into account neither the wishes of the person who died nor the complex web of factors that led to their decision to seek assistance in dying. It ignores society's responsibilities with respect to end of life care. It stigmatizes the person who provides the assistance and victimizes the person who sought death.

Ibid., s. 229.

Ibid., s. 745.

Ibid., s. 14.

Ibid., s. 241(b).

Ibid., s. 722(4).

Such perspectives are typically only considered as part of victim impact statements tendered during the sentencing process. 
What happens as a consequence of this approach is important. In some cases it turns an autonomous agent who sought assistance in dying into a victim, and a compassionate person who provided the assistance into a criminal. The jury is given what for many is a Morton's fork - either acquit even though guilt has been proven (and suffer the distress of disrespecting the law), or convict (and suffer the distress of knowing that a person who is no threat to anyone and who acted out of compassion in the face of intractable suffering will be sent to jail for a minimum of 25 years). What does not happen via such an approach is also important. There is no scope for a conversation about society's role in the decision to seek assistance with dying. For example, "[t]here are at least $70 \%$ of Canadians who do not have access to palliative care. And even when there is access, it is not equitable." ${ }^{13}$ Access to home care support services in the face of disease and disability is also intolerably low and inequitably distributed. ${ }^{14}$ There is also no scope to consider the impact on various groups within society, society as a whole, or on the multitude of relationships implicated in the decision to provide euthanasia or assisted suicide (for example, between patients and health care providers, patients and families, and groups with differing opinions on the acceptability of euthanasia and assisted suicide). While these facts could be critically relevant to why someone requested or provided euthanasia, and how euthanasia and assisted suicide should be treated by the law, they are considered irrelevant to the assessment of guilt.

A number of other consequences flow, not from actual criminal proceedings as discussed above, but rather from the risk of criminal charges and imprisonment following the provision of assistance in even the most compelling cases of euthanasia or assisted suicide ${ }^{15}$ (that is, from the Hobson's choice of (1) euthanasia or assisted suicide with the potential for dire penal consequences, or (2) no assistance in dying):

- $\quad$ Some individuals are made to endure avoidable suffering. Since death by painless lethal injection or consumption of a lethal overdose of medication is not available without dire legal consequences, some die in more rather than less painful ways and some endure longer rather than shorter periods of pain and other forms of suffering.

- Individual autonomy is violated as some are forced to continue living even when their lives are no longer worth living to them, and they are forced to die in ways not of their choosing.

- $\quad$ Equality is denied as those individuals who are physically capable of ending their own lives are free to do so, but those who have a disability that makes them physically incapable of ending their own lives without assistance are not.

The Honourable Sharon Carstairs, Raising the Bar: A Roadmap for the Future of Palliative Care in Canada (Canada: The Senate of Canada, 2010) at 3, online: Senator Sharon Carstairs <http://sen.parl. gc.ca/scarstairs/PalliativeCare/Raising\%20the\%20Bar\%20June\%202010\%20(2).pdf>.

14 A useful review of the state of home care in Canada is found in Canadian Healthcare Association, Home Care in Canada: From the Margins to the Mainstream (Ottawa: Canadian Healthcare Association, 2009), online: Canadian Healthcare Association <http://www.cha.ca/documents/Home_Care_in_ Canada_From_the_Margins_to_the_Mainstream_web.pdf $>$.

15 For example, a case involving an individual suffering from paralysis (including loss of the capacity to breathe) caused by amyotrophic lateral sclerosis or an individual suffering from intractable pain resulting from terminal bone cancer. 
- $\quad$ Some individuals may die earlier than they would if assisted suicide and euthanasia were not subject to such dire legal consequences - they may choose to commit suicide when they are still physically capable of doing so to avoid being unable to commit suicide if the suffering becomes unbearable at a point when they are no longer physically capable of committing suicide.

- The prohibition, coupled with the dire consequences of violating the prohibition, denies comfort that individuals may feel in knowing that euthanasia or assisted suicide would be available to them should their suffering become unbearable. As is clear from the data coming from Oregon (where assisted suicide is now legal), a significant number of people go so far as to seek the prescription that they can use for suicide, but never actually commit suicide. ${ }^{16}$ Considerable psychological comfort can come from knowing that autonomy will not be lost and an end to suffering will remain within one's grasp.

- $\quad$ Some individuals choose assisted suicide and die alone rather than with family or friends there to comfort them. They do this to reduce the potential of their loved ones being sent to jail.

- $\quad$ Some family members or friends of those who die as a result of assisted suicide or euthanasia suffer an extraordinarily high level of stress and distress as they help a loved one to die; they may suffer stress from the threat of criminal charges and consequential punishment and/or the distress of participating in an assisted death that is not peaceful or painless (for example, suffocating a loved one with a pillow) as more peaceful and painless methods are not available to them without increasing the risk of dire penal consequences.

- $\quad$ The perceived legitimacy of law is diminished as a criminal prohibition of euthanasia and assisted suicide with dire penal consequences is contrary to public opinion. ${ }^{17}$ No strong evidence-based or constitutional values-based arguments can be made by politicians to explain their ongoing refusal to engage in a serious attempt to find alternatives to life sentences for euthanasia and lesser jail terms for assisted suicide in Canada. ${ }^{18}$ Thus, the spectre of public policy decision-making based on the fear of single issue right-to-life activists threatens the public's perception of the legitimacy of law.

- $\quad$ It is possible that (assuming they know about the mandatory minimum sentence for murder ${ }^{19}$ ) juries will refuse to convict in cases of euthanasia even if they believe that it should be illegal, as they may feel that a life sentence in jail is an

In 2009, 95 prescriptions were written under the Oregon statute, 53 individuals committed suicide by using the prescription, 30 died of their underlying disease, and 12 remained alive, online: Oregon.gov $<$ http://www.oregon.gov/DHS/ph/pas/docs/year12.pdf $>$.

17 See generally supra note 5.

18 For a review of the arguments, see Jocelyn Downie, Dying Justice: A Case for Decriminalizing Euthanasia \& Assisted Suicide in Canada (Toronto: University of Toronto Press, 2004) c. 10-11.

19 See e.g. the description of the jury's reaction in Latimer when they found out about the mandatory minimum life sentence in Barney Sneiderman, "The betrayal of the Latimer jury: Supreme Court must restore public faith in a profound civic duty” The Ottawa Citizen (16 January 2001) A15. 
inappropriate response to a case of euthanasia. It is also possible that prosecutors will decide not to charge individuals with murder in cases of euthanasia or assisted suicide as they fear jury nullification. ${ }^{20}$ Thus, as a result, convictions will match neither the incidence of euthanasia and assisted suicide nor the apparently prohibitive regime envisioned by the Criminal Code. Some would argue that this is a problem per se, and others would argue that this is a problem because it will further diminish the perceived legitimacy of the law.

Thus, it can be seen that there are numerous problems with the current criminal justice approach taken to euthanasia and assisted suicide. In contrast to this approach, many have argued for the decriminalization of euthanasia and assisted suicide ${ }^{21}$ and been met by the intractable rancorous debate described above. However, there is an alternative approach that keeps euthanasia and assisted suicide in the Criminal Code but, we would argue, avoids many of the problems associated with the current approach as outlined above. There is an approach that we think holds significant promise for ensuring a better response to cases of euthanasia and assisted suicide and the difficult and important societal issues they raise. The alternative approach we explore and advocate in this article is that of restorative justice. Restorative justice has garnered a significant amount of attention in the last two decades, both nationally and internationally. In large measure, it has developed as an alternative to traditional criminal justice processes. ${ }^{22}$ As a result, restorative justice is often identified with its associated alternative practices/processes, for example, victim-offender mediation or reconciliation programs, conferencing, and sentencing circles. Restorative justice, so understood, represents a different way of doing the work of justice, but it has not received adequate attention for its broader implication, that is, for the different idea of justice it represents.

We see the potential of restorative justice for responding to cases of euthanasia and assisted suicide not only (or even primarily) as an alternative process, but also for the different conception of justice that underlies or supports such practices. We understand restorative justice and its potential as a theory of justice able to reveal what justice requires in response to euthanasia and assisted suicide both in substance and process. Downie, supra note 18 at 40 . One factor was "the fact that, if it went to trial, we would see ' 12 common folk from Timmins kind of chart the course for euthanasia at this point in time.,” Ibid.

Restorative approaches, however, are being employed far beyond the criminal justice realm. In the justice realm, restorative justice is being applied in civil suits, child protection, family law, and international human rights law. Restorative approaches are also being employed beyond the justice context in schools, workplaces, and neighbourhood disputes. Our conception of restorative justice, rooted in relational theory, makes it clear why it is not limited to the criminal justice context and indeed reveals the broader implications and applications of a restorative approach for social, political, and legal processes and institutions. 


\section{WHAT Kind OF JUSTICE IS RESTORATIVE JUSTICE?}

Restorative justice is a relational theory of justice. ${ }^{23}$ This means that it starts from an understanding of people and the world where relationship - connection rather than separation or independence - is foundational. Restorative justice proceeds from the assumption that we are relational beings; we are unavoidably connected with one another in various complex and multi-layered ways. It is not a predilection for relationships that drives restorative justice - not a conviction that relationship is a good or a goal in and of itself. Relationships can certainly be positive or negative. Rather, a relational orientation reveals that, for good or bad, they are. There is not then a choice to be made between relationship and no relationship. We are, on a relational theory, inextricably and by our nature, in basic and more robust ways, in relation with one another.

Relational theory pays serious attention to relationships and how they are structured, the effects they have on those involved, and what is needed from our relationships with one another to assure our well-being and flourishing. The work of justice understood relationally includes the identification of where harmful relationships exist or where harm has been caused to relationships. It seeks just relationships — what Jennifer Llewellyn has elsewhere referred to as "equality of relationship." 24 The goal is not to mirror certain archetypes of personal relationship. Justice here is concerned with the character of relationships that is fundamental in order for those in the relationships to thrive. Relationships with this character are those marked by equal respect, concern, and dignity. This is a measure of justice understood in a restorative way. A task of justice in each case is then to ascertain what is required by the context and circumstances of the parties affected by a situation to build restored relationships — relationships of equal respect, concern, and dignity. ${ }^{25}$

Restorative justice as a relational theory of justice rejects an individualistic approach to justice. Instead, it is grounded in a conception of human beings as relational. Such a conception does not focus on the collective over or against the individual. Rather, it posits a responsive relationship between the two. Individuals, on a relational conception, are formed and act in and through relationships with others. In the process, individuals shape and influence those very relationships. Restorative justice is not communitarian justice insofar as communitarian justice entails a deterministic role for community in relation to the individual. Restorative justice is concerned with individuals as they live in and through relationship. Individuals, on this view, still possess agency and thereby responsibility and accountability for their choices and actions. However, restorative justice does require attention to the fact that such choices are not made alone and have implications for and affect others.

23 This conception of restorative justice has been developed and advanced in Llewellyn's previous work: see e.g. Jennifer J. Llewellyn \& Robert Howse, Restorative Justice: A Conceptual Framework (Law Commission of Canada, 1998); Jennifer Llewellyn, "Justice for South Africa: Restorative Justice and the South African Truth and Reconciliation Commission” in Christine M. Koggel, ed., Moral Issues in Global Perspective (Peterborough: Broadview Press, 1999) 96. For a more general consideration of relational theory, see Jocelyn Downie \& Jennifer J. Llewellyn, eds., Being Relational: Reflections on Relational Theory \& Health Law and Policy (Vancouver: UBC Press) [forthcoming in 2011]. Within that volume, see especially Jennifer J. Llewellyn, "Restorative Justice: Thinking Relationally About Justice” [Llewellyn, “Thinking Relationally About Justice”]. 
Restorative justice is thus a different approach in both substance and form from the traditional approach through which society has, to date, dealt with the issues of euthanasia and assisted suicide. It is because of these differences that we think restorative justice stands to make a world of difference in how we understand and deal with cases of euthanasia and assisted suicide. In the remainder of the paper we sketch what difference we think restorative justice could make, consider how such an approach might be implemented, and reflect upon some of the challenges that might arise when trying to implement such an approach.

\section{THE DIFFERENCE THAT RESTORATIVE JUSTICE Might MAKE}

\section{A. A BROADER UNDERSTANDING OF HARM}

The current approach differs from a restorative justice approach in terms of how it identifies a wrong. The current criminal justice approach equates wrong (which warrants a justice response) with lawbreaking, and will see wrong in all cases of euthanasia and assisted suicide simply because there has been a breach of the law. Restorative justice, on the other hand, determines wrong on the basis of resulting and related harm. It is thereby capable of seeing that a wanted death may not have been harmful, and therefore would not constitute a wrong despite the fact that a law has been broken. ${ }^{26}$

The notion of harm is also different between the two approaches. Harm is understood relationally in restorative justice. Harm to individuals is important, but it cannot be fully appreciated without a sense of the harms that may result or be related in terms of an individual's relationships with others - the "offender," other "victims," their families, support communities, and broader society. By virtue of our relationality, harm to individuals affects those connected to them and the nature of their connection to others. Taking this broader view of harm and the extent to which it does not only reside in individuals means that you can more easily recognize harms to relationships (at micro and macro levels) absent direct harms to individuals. In the context of euthanasia and assisted suicide this creates space to consider the potential justice issues that may arise without having to get at them by establishing an individual victim or offender. There are cases where it might seem inappropriate to describe someone receiving what they want (an end to unrelievable suffering through a peaceful death at the time of their choosing) as a "victim" or a compassionate family member or doctor as an "offender.” We might nevertheless have concerns about the systemic or specific sets of circumstances that surrounded or prompted the choice to seek euthanasia and assisted suicide (for example, poor pain management, lack of family supports, and inadequate psychological support). Similarly we might remain concerned about the potential for broader societal harm, for instance, the erosion of respect for life or the implicit devaluing of certain members of society. Restorative justice allows for the recognition of, and response to, these potential harms. 


\section{B. ENHANCED ACCOUNTABILITY AND RESPONSIBILITY}

Restorative justice's relational approach to harm reveals a much broader set of potential "parties" (as those that are affected by or have a stake in the situation) who should be involved or engaged in the justice response to euthanasia or assisted suicide. Because of the focus on harm to relationships we can see how and why a broader set of individuals and groups might be affected. We can conceive of parties in meaningful ways that the traditional approach, with its adversarial logic, struggles to find. For example, the traditional approach easily accommodates offender and state. The recognition of the victim is more constrained and limited. ${ }^{27}$ By contrast, a restorative approach reveals the webs of relationship involved or affected by an incident and the fact that the harms extend beyond the deceased or the state to the families and support communities of both the deceased and the offender, other interest groups (for example, doctors, advocates for persons with disabilities, the end of life care community), and the broader public. The complexity of their connections and the effects upon them are not lost on restorative justice. Restorative justice not only broadens the view and categories of those involved, but also treats them as fluid and complicated. This might mean that the doctor who assisted with euthanasia or suicide is neither villain nor hero nor martyr, and a family who assisted may need compassion rather than condemnation. Since a restorative approach is not focused on ascribing blame (in justification of punishment meted out) it can seek accountability and responsibility in more nuanced, concrete, and specific ways. The complex picture of what happened and who was involved and affected in a given situation is what is required for a complete picture of responsibility, and thus for meaningful accountability.

One of the enduring critiques of restorative justice is that it is too "soft" of a response to crime. This critique grounds two concerns commonly expressed about a restorative approach. The first concern is that because restorative responses are not punitive they do not provide adequate consequences, and thus cannot convey moral censure of such acts and thereby discourage similar acts in future. The second concern is that the broader view of the context and causes of an incident serves to reduce individual offenders' responsibility - that it blames circumstances or society, and thus does not hold offenders accountable. On both counts the basis for the concern about restorative justice as being "soft" or inadequate justice is misplaced. It is true that a restorative approach is not punitive. Justice on a restorative account is not sought through laying blame and responding with what punishment is deemed deserved by virtue of the crime. But restorative justice is still concerned with responsibility and accountability.

For an account of the rise of the role of the state and corresponding exclusion of victims in the development of the Western legal system, see Harold J. Berman, Law and Revolution: The Formation of the Western Legal Tradition (Cambridge: Harvard University Press, 1983). Recent reforms to the criminal justice process have sought to accommodate some role for victims within the process. For a discussion of these inclusionary reforms, see Bruce P. Archibald, "Coordinating Canada's Restorative and Inclusionary Models of Criminal Justice: The Legal Profession and the Exercise of Discretion under a Reflexive Rule of Law” (2005) 9 Can. Crim. L. Rev. 215 at 228. However, the spaces created within the criminal justice approach are still marginal. For the most part their involvement is still structured to support the state through testimony at the trial stage, or at the sentencing phase through victim impact statements. While modern reforms have become more inclusive of victims they have not brought the victim into the process in the central or significant way that is offered by restorative justice processes. 
Restorative responses are centrally concerned with understanding and addressing the harm resulting from a wrong. Those who have caused or contributed to the harm have an obligation within a restorative justice approach to understand the effects of their actions so that they can play an active role in figuring out how to address the harms. Requiring an active role of those who have caused harm contributes to a stronger notion of responsibility and accountability within restorative justice. Responsibility is not simply assigned or ascribed in restorative justice processes, but must be understood and accepted by those involved. Individuals are not simply held accountable by the traditional approach of externally imposed conviction and punishment. Rather, a restorative justice approach achieves more significant accountability because individuals accept responsibility and then participate actively in addressing the harm they have caused. This accountability is often made even more meaningful because it happens in the context of processes that involve those that these individuals care about and respect. It is not a system holding offenders to account through formal and one-size-fits-all mechanisms. Restorative justice approaches require that those who cause harm be accountable through participation and action. The requirement to address the harm resulting from one's action means that while restorative justice does not respond to those who have caused harm with punishment, it does entail consequences for those who cause harm. Such consequences are not imposed on them by others, but rather are agreed to by the individual who caused the harm. The consequences are not for the purpose of causing an equal measure of harm, but rather come about because of the obligations to address the harm generated by the harmful act.

The concern that restorative approaches are too soft also stems from the fact that, through their relational approach, restorative justice processes may not ascribe responsibility exclusively to the individual wrongdoer. Restorative justice processes attend to the contexts, causes, and circumstances of the act that might reveal a more complex story about responsibility for the harms. This broader picture may mean that responsibility for what occurred is shared. The worry is that this might let the individuals who are largely responsible off lightly, or perhaps even free. Even if they are still seen as partly responsible, critics might argue, the ability to shine the light of responsibility elsewhere will reduce accountability for those individuals most responsible. With an approach like the traditional one, where calculating the quantum of blame is essential for legitimizing and meting out punishment, this concern about a more nuanced and complex picture of responsibility might be serious. But a restorative justice approach is not focused on laying the ground for punishment. It is concerned with ensuring responsibility and accountability so that the harms resulting from the wrongful act can be appreciated and addressed in order that restored relationships can be built. This goal requires a more complex picture of responsibility, not in order to let any party off easier, but so that those who bear some responsibility for the situation can play a part in addressing it and building a better situation for the future. If there are other relevant causes and circumstances beyond the control of an individual wrongdoer (for example, inadequate health care services), it would be unjust and ineffective to lay the burden of redress upon the individual alone. Recognizing shared responsibility ensures that the actual responsibility of the individual and all others involved is accurately reflected in the response. This may mean in turn that the individual charged with an offence accepts accountability and the resulting consequences. Insofar as these other factors, contexts, and circumstances are deemed irrelevant by the individualistic focus of the traditional approach, 
the risk is that, in taking that approach, law's legitimacy is reduced and the law's response will not restore relationships.

The other way in which the traditional approach seeks to assure accountability is through the moral censure that comes through punishment. As the above discussion reveals, restorative justice does not forgo accountability or consequences for one's actions. The argument for the importance of punishment for the sake of moral education sometimes rests on the assumption that a choice is required between punishment and no response. But restorative justice does not make such a choice. It does forgo punishment, but it ensures meaningful response to harm in the form of active participation in reparation of harm. In this way, restorative justice challenges the identification of punishment with accountability. A similar challenge is made to the claim that punishment is required to communicate the moral message that certain acts are unacceptable. Not only are restorative processes capable of conveying this moral message (by virtue of ensuring a response to a wrong that requires the active participation of those responsible) but, by their nature, restorative processes might be better at the task of moral communication and education. Quite simply, relying on punishment to convey moral messages can be an ineffective form of communication. Restorative processes actually create processes in which actual (rather than symbolic and virtual) communication between and among the parties (the victim, offender, their support communities, interest communities, and the broader society) is possible, and indeed probable. Moral messages can be conveyed, heard, and actually reflected upon within a process that does not rely on punishment as a surrogate. Further, the fact that restorative processes involve more than just the individual wrongdoer means that these messages can be communicated to a wider audience, thereby affirming societal values. ${ }^{28}$

In the context of euthanasia and assisted suicide this is particularly important given that one of the serious concerns about the apparent failure to prosecute cases to the fullest extent of the law $^{29}$ is an erosion of the sanctity and respect for human life and, in more specific circumstances, concern that certain members of society (the elderly or persons with disabilities) might be devalued. This same concern motivates some to argue that punishment of euthanasia and assisted suicide is essential. Punishment sends a message about the seriousness and importance of respect for, and protection of, human life. By punishing these acts, the state declares them to be of public concern and a matter of public order and safety. Punishment is also seen as a means of ensuring accountability since it brings the resources of the state to bear in the bid to hold offenders accountable. However, in the case of euthanasia and assisted suicide, such an approach has arguably had the opposite effect than intended. Criminalization (particularly where it is accompanied by mandatory minimum sentences) is a very blunt instrument. It requires stark choices - prosecute or not, find guilty or not, stigmatize or not. In the face of what are often morally complex cases where criminalization cannot accommodate more nuanced responses, police, prosecutors, judges (and sometimes juries) are left in very difficult positions. This difficulty is perhaps most acute for prosecutors, as they are charged with exercising their discretion to pursue a case in the public interest or not. It is not always clear-cut that prosecuting euthanasia and assisted 
suicide cases under the current regime will serve the public interest, particularly where the evidence makes prosecution difficult or where the culpability of the individual accused is neither clear nor theirs alone. Yet with the decision not to prosecute, an opportunity to consider the broader context and circumstances of the case and its implications for law, policy, and public values is lost.

Of course a restorative justice process does not always avoid prosecution and punishment. Restorative processes can be used as an alternative to criminal charges, thus avoiding criminalization of the specific acts. Typically this would mean that no criminal record would be generated as a result of a restorative process. This would be the case where restorative processes are undertaken pre-charge (typically referral by the police) or pre-trial (referral by the prosecution). But restorative processes can also be employed at later stages in the traditional process (for example, referrals by judges at the sentencing stage or by corrections officials as part of a rehabilitation or re-entry plan). Since restorative justice represents a different way of thinking about justice and its demands, it is a better fit earlier in the traditional process as, essentially, a diversion. As a case proceeds through the traditional process, the focus on harm caused is obscured and the more nuanced and meaningful processes of responsibility and accountability are lost. The later restorative justice enters the process, the more work is required to undo the individualistic logic of the traditional approach. However, while preferable to undertake a restorative approach to justice from the outset of a case, it is still possible for restorative approaches to be of some benefit later in the process. A restorative justice approach, for example, might be able to carve some space for a more nuanced understanding of what happened (beyond the mere actus reus of the offence) and what remedies might be appropriate. ${ }^{30}$

There is another way in which the use of restorative justice processes in place of the traditional approach is helpful - they are more likely to assure a response to cases of euthanasia and assisted suicide. The blunt instrument of the traditional approach leaves prosecutors little choice if they feel the public interest is not served by prosecution - either charge the accused or make no response. However, by avoiding the stigma and rigidity of the traditional approach, a restorative justice approach is more likely to lead to a response to cases of euthanasia and assisted suicide.

\section{A Proactive And Preventative Focus}

As mentioned in the discussion above, the focus of a restorative justice approach stands in contrast to the traditional approach. The traditional approach is primarily backward focused. It is concerned with ensuring that offenders pay for their past deeds. It is focused on balancing the scales through the meting out of punishment that "fits" the crime. The focus is on past deeds and what is deserved in response. By contrast, a restorative justice approach is primarily future focused. This does not mean that, in a restorative process, what happened

30 One of the serious potential challenges for the use of restorative justice later in the criminal justice process is the existence of mandatory minima that require not only punishment, but a particular form that is isolating and generally harmful to the prospect of building respectful relationships marked by dignity and mutual concern. This is a challenge that exists in the context of euthanasia as it is currently treated within the Criminal Code. One of the advantages of introducing a restorative justice approach earlier in the process is that it opens space to consider more appropriate responses/consequences that can better contribute to restored relationships in the future. 
or what was done in the past is unimportant. What happened or what was done in the past is central to the process, but for a different reason than within the traditional approach. A restorative justice approach cares about what happened in the past in order to understand the implications and effects of the deed (the harms that resulted) and the context, circumstances, and factors that contributed to the situation. A restorative process would, for example, absolutely canvass whether the person given assistance to die was competent, made the request freely, was in pain that could not be relieved, and had been given alternatives. It would also canvass what services were available, who was involved in the decision-making process and the euthanasia or assisted suicide, and why. A restorative process seeks this understanding not for its own sake or in order to ascribe blame and a deserved response but, rather, in order to craft a different future. The aim of restorative justice is the establishment of restored relationships for the future, not evening the score for past wrongs. Such relationships require that past harms and unjust relationships be understood, addressed, and transformed, and the past is relevant in this way.

One of the advantages of the future focus of restorative justice is that it is consciously concerned with deterrence and prevention. However, it does not rely on negative incentives to avoid future behaviour. Rather, it seeks to create the conditions in which future harm is less likely. The traditional approach pursues deterrence through the use of punishment despite the continued failure to prove the hypothesis that more and harsher punishments will deter. Restorative justice processes operate on a different hypothesis (one with more empirical credibility), that the more one is embedded in a web of relationships of equal respect, concern, and dignity, the less likely one is to cause harm. In the case of euthanasia and assisted suicide the immediate concern is less often with specific deterrence (that the same person will commit the act again, with the possible exception of where a health care provider is involved), but with general deterrence (the fear that this behaviour will serve as a bad example for others in society who might be inclined to the same behaviour).

Restorative justice processes are also more likely to serve the interests of general deterrence than the traditional approach. First, insofar as officials are more likely to proceed with a case where they can take a restorative approach than when they must take the traditional approach, the surety of a response is more likely to deter others than is the current uneven and unpredictable enforcement regime. ${ }^{31}$ But beyond such practical concerns, by virtue of their capacity to involve the broader public and to conduct meaningful reflections on the moral and legal issues involved, and to communicate these to the public, restorative justice is better able to influence behaviour of others. ${ }^{32}$ Also, because restorative justice processes look at all of the relationships implicated in the case, and are therefore able to consider the range of factors that might have contributed to, motivated, or enabled the situation, the factors might actually be addressed so as not to contribute to similar choices or situations in the future. For example, if one of the issues in a particular case was inadequate support for end of life care or home support for parents of children with profound

See Downie \& Bern, supra note 29 , for a summary of the cases.

See generally John Braithwaite \& Philip Pettit, Not Just Deserts: A Republican Theory of Criminal Justice (Oxford: Oxford University Press, 1990); John Braithwaite, Crime, Shame and Reintegration (Cambridge: Cambridge University Press, 1989); John Braithwaite, Restorative Justice \& Responsive Regulation (New York: Oxford University Press, 2002); Lawrence W. Sherman \& Heather Strang, Restorative Justice: The Evidence (London: Smith Institute, 2007). 
health issues, a restorative process can deal with these issues as a central concern of what justice requires and contribute to changing the factors that might lead to similar situations in the future. Similarly, if a lack of knowledge about appropriate and available treatments or competency assessments is at issue in a particular case, a restorative process could focus on improving the education of health care professionals.

Restorative justice responses to specific cases, then, are capable of considering the broader issues that surround the situation and are relevant to preventing or replicating situations in the future. The individual backward looking focus of the traditional approach does little or nothing to address such issues as part of its search for justice. Insofar as they are revealed, it is usually by chance or outside of the justice process. This is yet another reason to commend the use of a restorative approach in the context of euthanasia and assisted suicide. In their reaction to specific circumstances, such processes are able to be proactive and preventative. Through such processes, the parties can reflect upon relevant law and policy and consider its role and adequacy. As we discuss in the next section, restorative justice processes are democratic in character and function. What is significant about such processes for law and policy relating to euthanasia and assisted suicide is that they can serve as a democratic feedback loop of sorts about current law and policy. Such processes thus have the potential to provide democratic input into law and policy-making and reform.

\section{A More Inclusive, Participatory, ANd Democratic Process}

Throughout the foregoing sections of the article, a picture of restorative justice processes has emerged. As mentioned earlier, it is important to see the potential of restorative justice to respond to cases of euthanasia and assisted suicide as flowing from the fact of it being not only an alternative process, but also an alternative understanding of justice. The substantive understanding of justice and what it requires has clear implications for justice processes. One of the implications that is sometimes lost amidst detailed descriptions of restorative justice encounter processes (victim-offender mediation models as well as the more robust conferencing or circle processes) is that these moments of structured encounter are not the totality of a restorative process. Encounter processes are important within restorative justice, as we will discuss below, because they provide an opportunity for parties to meet and participate together in a dialogical process to craft an outcome that will address the harm and work to restore relationships. As important as they are though, encounter processes on their own cannot achieve restorative justice. The success of such processes relies on a careful and thorough preparation of the parties (which may include building their capacities to participate in such a process). Fundamentally, encounter processes lay the foundation for the work of restoring relationships both by modeling and giving parties an experience of positive relationship with one another, and also as a means of crafting the outcome agreements to be carried out by the parties. These agreements often set out the work needed to move towards restored relationships. What follows such encounters is the "doing of justice.”

In some sense our traditional justice vocabulary is inadequate to restorative justice. We talk of justice being done, but the nature of relationships is that they are never static and rigid - they are fluid, dynamic, and ever-changing. Thus, on a relational conception of justice, it is more accurate to describe justice as something we do, and must keep doing, rather than something done. Certainly a just response can be made to a given case and it can contribute 
to the achievement of just relationships. This nature of restorative justice then will have implications for its practice. The non-static nature of relational justice requires that as much attention be paid to preparation and follow-up as to the encounter process itself. It also means that a restorative justice process should be conceived of as more than a one-off conference or meeting. It will involve preparation and follow-up work but also, depending on the situation and the relationships affected, it may involve more than one encounter in a given process. One might have to bring the same parties back together more than once to arrive at an acceptable outcome plan or it may be appropriate, in a complex case, to have different processes to deal with the distinct issues or harms involved.

Three process elements most clearly differentiate restorative justice processes from processes that flow from the traditional approach. Restorative justice processes are more inclusive, participatory, and democratic. The inclusivity of restorative justice processes is demanded by the broader set of parties seen to be affected or interested in the resolution of a situation. As discussed above, a restorative justice approach reveals that the parties to a situation cannot be limited to the offender and the state, or even the victim, offender, and the state. The harms associated with the situation extend beyond these parties, and the contexts, causes, and circumstances of the situation have broader implications and effects. The goal of a restorative justice process is to restore the relationships affected and, in order to do so, such processes must include all those affected and all those required to achieve such a restoration. In the case of euthanasia and assisted suicide, we could imagine, for example, that those who should be involved would include the accused, their supporters (including family, friends, and/or colleagues), the person who died (often referred to as "the victim," but we reject this label as it belies the fact that in many cases the death was desired), that person's family, friends, and/or supporters, and others who are affected or harmed. Restorative justice can comprehend different parties and the different ways in which parties might be harmed. For example, those harmed might include the family or friends of the person who died or representatives of those similarly situated (for example, if the person had a disability), other interest communities directly concerned or involved, and the general public or state. One of the advantages of a restorative approach is that it might also provide more nuance and guidance as to which state actor(s) should be involved. For example, it might not be a prosecutor. Given the situation, it might be more appropriate for a representative from the Departments of Health and/or Justice to participate. A health official might be far better placed to contribute to an understanding of what happened and why, and the process of designing a fitting response to the situation (including, perhaps, actions to be taken by the Department of Health).

Yet mere inclusiveness does not make a process restorative; those included must also participate in the process. Restorative processes do not simply seek input from different parties in order to determine or adjudge an outcome. Rather, the process is a collective one. With the assistance of a facilitator, the group must work to come to an agreement about how to respond to the situation. There are, of course, some limits on the allowable outcomes they must be consistent with the substantive goal of restorative justice in establishing relationships of equal respect, concern, and dignity.

The commitment to participation, then, might best be described as “democratic.” By "democratic" we obviously do not mean that parties vote within the process. Rather, we 
invoke the concept in its more robust sense of participation in decision-making. ${ }^{33}$ Restorative justice processes are not only democratic in terms of their nature, but they can also serve a democratic function. As a result of their inclusive and participatory nature (which considers the harm, its context, and its causes), and their future orientation, restorative processes provide a venue in which to reflect upon the law and its application and implications. These reflections can then be fed back into law-making and reform processes, thus serving as part of a democratic feedback loop. The traditional approach to prosecuting cases of euthanasia and assisted suicide, by contrast, lacks these inclusive, participatory, and democratic features.

\section{BUILDING A RESTORATIVE RESPONSE TO EUTHANASIA AND ASSISTED SUICIDE}

The preceding consideration of restorative justice and what it might bring as a new approach to euthanasia and assisted suicide provides a basis from which to consider what a process or program to deal with these cases might look like in practice. Restorative approaches, as they seek to restore the relationships at stake in a given situation or with respect to a particular issue, must be grounded in and attentive to the particular contexts and circumstances to which they are being applied. Furthermore, restorative principles must guide the development of specific restorative processes or programs. ${ }^{34}$ For these processes to be appropriate and successful, it is important that there is input from the parties most concerned at the design phase as well as within a process to address a particular case. Designing a program to deal with euthanasia and assisted suicide should therefore involve participation by those with a general or particular interest in the issue. For example, physicians, nurses, and other health care professionals, as well as organizations representing individuals with particular diseases or conditions and individuals with particular views on the moral issues implicated in euthanasia and assisted suicide. Their participation in the design of such processes will ensure that the resulting processes are able to effectively deal with the issues for all affected. It will, for example, bring expertise to bear about issues of timing, location, potential power imbalances, or capacity issues that would need to be addressed and a sense of the scope of the process including which parties, expert supports, and other resources might be needed and available for the process. Involving the stakeholders in a meaningful way in planning such a process or program is also more likely to assure willing participation in future processes and their legitimacy. If parties have input into the design of a process, they are more likely to identify it as fair and be willing to respect its results. $^{35}$

33 Jürgen Habermas' work on discourse and democracy might provide some important insights here. See generally Jürgen Habermas, Between Facts and Norms: Contributions to a Discourse Theory of Law and Democracy, trans. by William Rehg (Cambridge: MIT Press, 1996); Jürgen Habermas, The Theory of Communicative Action: Reason and the Rationalization of Society, vol. 1, trans. by Thomas McCarthy (Boston: Beacon Press, 1984); Jürgen Habermas, The Theory of Communicative Action: Lifeworld and System: A Critique of Functionalist Reason, vol. 2, trans. by Thomas McCarthy (Boston: Beacon Press, 1987). An example of this idea of democracy was articulated by the Supreme Court of Canada in Reference Re Secession of Quebec, [1998] 2 S.C.R. 217.

$34 \quad$ Llewellyn \& Howse, supra note 23 at 42. See also Jennifer J. Llewellyn, "Restorative Justice in Transitions and Beyond: The Justice Potential of Truth-Telling Mechanisms for Post-Peace Accord Societies” in Tristan Anne Borer, ed., Telling The Truths: Truth Telling and Peace Building in PostConflict Societies (Notre Dame: University of Notre Dame Press, 2006) 83.

35 Significant attention has been paid to this idea since John Thibaut and Laurens Walker's early work on procedural justice, Procedural Justice: A Psychological Analysis (Hillsdale, N.J.: Lawrence Erlbaum Associates, 1975). Since that time, the proposition has been tested and affirmed: see e.g. W. Chan Kim \& Renée Mauborgne, "Fair Process: Managing in the Knowledge Economy" (1997) 75:4 Harvard Business Review 65. 
One of the other potential benefits of bringing together interested parties for a discussion related to the design of a restorative program is that it provides an opportunity for those with very different perspectives on the issues to be clear about what the real concerns are that should be taken up in a restorative process. ${ }^{36}$ This sort of open communication is less likely to occur in the current context, where the definition of what justice entails is structured by the traditional approach to prosecuting criminal offences.

The operative definition of justice in the current system often shapes our desired outcome and position. Here the case of Robert Latimer is instructive. ${ }^{37}$ Many advocates for persons with disabilities were actively involved in discussions of this case through the media. Their concern was the potential erosion of respect for the lives of those living with profound disabilities and the precedent that Latimer might set for other families. But instead of being able to address that issue directly and consider an outcome for that case which would address that concern directly, the only measure of justice available through the traditional approach was Latimer's sentence and time served as recognition of the seriousness with which the state took the concern. Unfortunately, in the end, Latimer's imprisonment did little or nothing to improve the lives of those like his daughter Tracy, or families in similar situations. It also did very little to change the culture or societal views of disability in ways that advocates sought. Rather than being able to take a position in favour of an outcome that would address the harms at the heart of their concern, advocates spent most of their energies and political capital seeking the justice that was on offer — a prison sentence for Latimer.

In light of our commitment to restorative principles in the design as well as conduct of restorative processes, it is not possible to offer a ready-made model for dealing with euthanasia and assisted suicide. Such processes/programs may well differ from one context/jurisdiction to another and still be entirely restorative so long as they reflect the substance and process principles of restorative justice. But this does not mean that there is no guidance we can offer to suggest a program for initial consideration and identify issues that would warrant careful attention in the design of such a program. Indeed, there are models of restorative justice programs that would provide a sound and informative basis from which to develop a restorative response to euthanasia and assisted suicide cases. In the Canadian context, perhaps most helpful in this regard is the Nova Scotia Restorative Justice Program (NSRJP). ${ }^{38}$ Piloted in 1999, the NSRJP was in full operation throughout the province by 2001. In its first two phases, the NSRJP was intended to apply to youths ranging from 12-17 in age (under the jurisdiction of the Youth Criminal Justice Act ${ }^{39}$ ). Having had success with young people, the NSRJP is about to enter its third phase - pilot use with

Broadening the scope of what is at stake in such cases also creates opportunities for alliances and allies on issues related to the protection and respect for life and the supports needed to assure it.

See Downie, supra note 18 at 40-41, for a description of the case and citations to the multiple decisions emanating from various court levels.

For more detailed information about the NSRJP, see Bruce Archibald \& Jennifer Llewellyn, "The Challenges of Institutionalizing Comprehensive Restorative Justice: Theory and Practice in Nova Scotia” (2006) 29 Dalhousie L.J. 297. There are other instructive and helpful models. For example, in the Canadian context insights might be drawn from the Collaborative Justice Program in Ottawa. This program was co-located with the Provincial Court in Ottawa and took referrals from the Court related to serious adult offences. For information about the program, see online: Collaborative Justice Program $<$ http://www.collaborativejustice.ca/ $>$.

S.C. 2002, c. 1 . 
adults. This recent development would also open up space to consider its use with respect to euthanasia and assisted suicide.

The Nova Scotia model is a helpful one for consideration in this context for a number of reasons. First, it has entry points at each stage of the traditional criminal justice process: charge, prosecution, sentencing, and corrections. Thus, each of the system actors (police, prosecutors, judges, and corrections officials) can make a referral to the NSRJP. This model would work well for euthanasia and assisted suicide as it would allow referral of cases at various stages to respond to different sorts of concerns. It would also allow for euthanasia and assisted suicide cases to be treated in a traditional fashion in circumstances that would not be amenable to a restorative justice approach — for example, where the person accused as the provider or assistant disputes the allegation and wishes to prove the alleged facts at trial, or where the individual is not ready or able to participate in a restorative process. Generally, the inappropriateness of a restorative process in a particular case will be fairly easy to ascertain because the individual will simply refuse to take part, an assessment reveals that the individual is not psychologically ready or able to participate, or there is an assessment of threat or danger if the person is not subject to incarceration. But, given what we know about euthanasia and assisted suicide cases, ${ }^{40}$ such situations are likely to be rare. For the majority of those involved in these cases there will be no such barrier to participation. However, it is important to highlight that restorative processes are voluntary processes. Because they rely upon the active participation of the parties, and ultimately their willingness to work towards addressing the harm caused and restoring relationships, it is not possible to force this or require it. While it is possible to punish an unwilling subject, the work of restoring relationships cannot be forced.

Another instructive feature of the NSRJP is the roles and relationships of government and community actors within the NSRJP. Because restorative justice programs should be embedded in the contexts they seek to respond to, it would be very difficult to operate a restorative justice program wholly within a government system that was not grounded in community. Such a state-owned model would also pose problems for its top-down character. A relational approach cannot be forced or handed down but, rather, to have legitimacy and access to the information it needs to be responsive to the relationships affected, it needs to be rooted in community. However, the reverse proposition — that of restorative justice wholly owned by the community with no state involvement — is not ideal either. Quite apart from the precarious position this might cause in terms of resource stability, the lack of state involvement would be a potential problem for other reasons. Without state involvement, programs may not be accessible or equitable in their treatment of all. The state (at least in Canada) has an important role to play with respect to rights protection. Ideally, the quality of programs would be assured for all those who access them, even in different communities. The state thus has a role to assist in the establishment and enforcement of standards for a program. It is therefore useful to consider a model such as that used in Nova Scotia because the state and communities are partners in the NSRJP. The state sets out, facilitates, and oversees the program, but the program is animated, developed, and implemented in the

40 See descriptions of cases in the Right to Die Society Researchers’ Buffet on Assisted Suicide in Canada and Compassionate Homicide in Canada, online: Right to Die Society of Canada <http://www. righttodie.ca/>, and in the case-specific references provided therein. 
various communities throughout the province by community-based agencies. The fully regional model may not be best for a program dealing with euthanasia and assisted suicide (for reasons such as the likely low case volume), but the important point is that some community insights and participation in the program are key to its acceptance and success.

The challenges and weaknesses of the NSRJP are also instructive. One of the significant drawbacks of the NSRJP is the streaming of referrals based on the level or type of offence. The NSRJP determines the point in the traditional process at which an individual can access the program by virtue of the type of offence committed (or charged). The system thus attempts to ensure that the more serious offences are referred later in the criminal justice process, with the result that some types of offences cannot be referred until after a conviction has been entered. The problem with this system is not that there might be some cases that are not amenable to restorative justice early on and that need to progress through the traditional process further before being referred. The problem is with the use of the level or type of offence as a basis to make this determination. A restorative justice approach draws one's attention to the seriousness of the harm caused and the willingness and capacity of the parties involved to address the harm with a view to restoring relationships. The level or type of offence does not always accurately reflect its seriousness in terms of harms caused.

Nor does it accurately predict the appropriateness of a case for a restorative justice approach. Streaming cases in this way gives "low end" cases greater access to restorative process (they can be referred at earlier stages and fully diverted from the traditional process). Not only is this manner of streaming cases a poor reflection of the seriousness of a case in terms of harm or its amenability to restorative justice, it also might lead to the impression that restorative justice is only appropriate in cases of low harm and should be avoided where there is more serious harm — for example, cases involving interpersonal violence. However, recent evidence suggests that, contrary to common assumptions, restorative approaches work particularly well in the cases we tend to consider to be more serious. ${ }^{41}$ This issue of the design of restorative programs is particularly important with respect to euthanasia and assisted suicide. Given the level or type of offence that they represent, they would be assumed under a streamed system to be serious and thus appropriate for referral only at the later stages of the traditional criminal justice process. This pre-empts one of the central issues of importance in such cases: the assessment of the level and nature of the harm involved. Some cases of euthanasia and assisted suicide will not involve a high level of actual harm to the parties involved, although they may warrant attention for the potential harm of failing to fully understand the situation and address any issue that might have influenced the decisions in ways that are of concern. These cases should not be streamed as amenable for a restorative process only once dealt with through the traditional process. Indeed, given the interpersonal relationships often involved in these cases and the grief that is often involved in the loss of a loved one, it may cause harm where there is little reason to delay instigation of a restorative process. Even where there is harm (where, for example, there may have been disagreement within a family or between a physician and family), it is the sort of interpersonal harm that restorative processes deal with particularly well. 
Designing a restorative justice response for euthanasia and assisted suicide will require careful attention to several other issues that bear some comment here. First, it will be important to develop a strategy or approach for who (in general) should be included as parties within the process. Of course, the participants will and should differ depending upon the case. It is, however, important to consider who the parties will be in a general way for two reasons. First, it frames where to look to invite parties to participate. It is very easy in a new approach to fall back on the assumptions of a more familiar approach, in this case the current criminal justice system's sense of who has a stake in the matter. These assumptions would lead one to focus primarily on the traditional categories of offender, victim, and state. But as is evident from the above discussion of restorative justice, it requires a much broader conceptions of parties. Second, it is important to consider who might be parties in order to think through some of the complexities and process challenges that might develop in cases where there are a large number of parties wanting to participate. This might be a particular concern where the broader societal issues seem to loom larger than those harms related to the incident itself. In such cases, consideration should be given to how to address both concerns without undue burden (which might be harmful) to the direct parties.

Another, but perhaps related, issue that should be considered is that of confidentiality. This issue sometimes arises as a result of the relationships between restorative processes and traditional criminal justice processes. If restorative justice processes are conducted as referrals from the traditional processes, the case can be returned to the traditional process either at the request of the accused or if a satisfactory result cannot be found through the restorative process. In these circumstances, the issue of confidentiality is sometimes raised as a concern about whether information from the process might be used in court should the case be returned to the court. However, while this is an evidentiary question that should be resolved, it is not fundamentally one of confidentiality. Unfortunately, confusion on this issue leads some to assert that restorative justice processes should be confidential. Those who make such claims are also sometimes influenced by the practice of protecting confidentiality in civil alternative dispute resolution processes. However, those processes are significantly different from restorative justice processes. They are aimed at the private settlement of a private legal claim.

The logic of confidentiality in such circumstances is that one is more likely to reach a deal in secret. That may be fine if the goal is to settle or reach a deal, but that is not the ambition of restorative justice. Restorative processes have a substantive justice goal of the restoration of relationships and their focus is primarily on the social relationships (narrowly and broadly understood) involved in the situation and not centrally concerned with the personal/intimate relationships between specific parties. This goal cannot be served by private justice restorative justice is inherently about public justice and it is thus important that restorative justice processes be kept public. Court proceedings are public for these very same reasons. It is important that justice be done and be seen to be done; in the seeing of it, societal values and the commitment to justice are affirmed. Of course, there will be exceptions where there may be some significant harm caused by a public process or where the public may have to take a limited role if the demand to participate is overwhelming, and these exceptions could 
also be made under similar circumstances in restorative justice processes ${ }^{42}$ But even in these cases, efforts should be made to, if possible, make the outcome agreement or relevant information about the direction and outcome of the process publicly accessible.

It will also be important to consider what should happen if certain parties, who are clearly centrally affected by the event, do not wish to take part. Should their refusal serve as a veto on the process? There are some serious issues to consider in terms of fair treatment if access to a justice process is at the mercy of another involved party. However, a restorative approach does provide some explanation for why and how a process might proceed even without all of the parties. Quite simply, a restorative approach reveals that there is more than one relationship or set of relationships generally affected in a case. For example, even if the family of the person who died does not wish to take part, there might still be harms experienced by the accused's family, community, or the broader society that need to be addressed. In a case of euthanasia, the health care professionals involved in the case as well as other health care professionals in the same facility might have been greatly affected.

Finally, it will be essential in the context of euthanasia and assisted suicide that the caseworkers, facilitators, and others involved in implementing such an approach receive good training in the issues related to euthanasia and assisted suicide. In part, this is so that they can be alert to the issues as they present themselves and ensure that the parties and the process are prepared to handle them. However, it is also important in order to address the stigma, prejudice, and other assumptions they might have regarding the issues involved.

\section{CONCLUSION}

In the end, we can see that taking a restorative justice approach to euthanasia and assisted suicide might provide us with a path away from intractable discord toward compassionate compromise. By taking a restorative justice approach, euthanasia and assisted suicide remain illegal and there is a clear statement being made by society that it believes they should be avoided. However, the approach compels us to look at all of the factors involved in the decision to seek and provide euthanasia or assisted suicide. It allows us to find that, in some circumstances, euthanasia or assisted suicide are entirely inappropriate, the person who died was harmed, and the social fabric was ruptured. It also allows us to find that, in other circumstances, euthanasia or assisted suicide are a reasonable response to an unreasonable situation, the person who died was not harmed, and ruptures in the social fabric were causes rather than consequences of the unreasonableness of the situation. The appropriate response in the former situation may be a finding of responsibility and a call for accountability from the person who provided the assistance in dying. The appropriate response in the latter situation may be to provide grief counselling and support to the family and friends of the person who died and to call for changes to the aspects of the health care system that allowed the person's situation to be such that their life was no longer worth living to them. A restorative justice approach opens our eyes so that we take more into consideration, it opens doors so that more individuals and organizations affected by the situation are engaged, and

42 Note in these cases though that this is valuable information for the state to consider, which perhaps demonstrates that it is an issue about which a broader, more public process should take place outside the confines of a particular case. For example, an inquiry process could be used (but one structured restoratively). 
it opens the possibilities for ways in which to respond so as to ensure that we have a system built upon relationships of equal respect, concern, and dignity. 